Article

\title{
Measuring the Value of Farmland-Elevating Engineering in the Reservoir Area of a Key Water Conservancy Project in China
}

\author{
Jiyong Ding ${ }^{1}(\mathbb{D})$, Wujuan Zhai ${ }^{1, *(D)}$ and Leichuang $\mathrm{Hu}^{2}$ (D) \\ 1 Institute of Engineering Management, Hohai University, Nanjing 211100, China; jyding@hhu.edu.cn \\ 2 China Three Gorges International Corporation, Beijing 100033, China; hu_leichuang@ctg.com.cn \\ * Correspondence: wjzhai@hhu.edu.cn; Tel.: +86-25-6851-4710
}

Received: 25 March 2018; Accepted: 14 May 2018; Published: 18 May 2018

\begin{abstract}
With the development and construction of key water conservancy projects, many problems such as population migration in reservoir areas have become increasingly grave in China. The implementation of farmland-elevating engineering has become an effective way to reduce the loss of cultivated land, prevent soil erosion, and ensure food security and social stability. On the basis of the key technical analysis of farmland-elevating engineering, this paper constructed a value system of farmland-elevating engineering from aspects of social value, ecological value, and economic value and established corresponding measurement models, respectively. Taking a key water conservancy project in Jiangxi province as an example, this paper measures the value of farmland-elevating engineering implemented in this project. The results show that the implementation of farmland-elevating engineering can produce great value. This study aims to provide reliable references for the decision-making regarding farmland-elevating engineering.
\end{abstract}

Keywords: farmland-elevating engineering; measure of value; water conservancy project; social value; ecological value; economic value

\section{Introduction}

In recent years, the construction of water conservancy projects in China has made great achievements that attract worldwide attention. However, a series of problems have also arisen in the construction process. The rise of water storage level affects the surrounding ecological environment and cultivated land and causes large-scale loss of soil and water. The increase of ecological migration population makes the resettlement problem become one of the most difficult problems in water conservancy projects [1]. As a new type of technical measure to protect cultivated land, farmland-elevating engineering was put forward through which the farmland is lifted to the non-submerged elevation of the reservoir and meets the requirements of agricultural production. It is the most economical, reasonable, and effective measure to reduce submergence of cultivated land and thus reduce the size of resettlement of affected residents. It is in line with the concept of sustainable development. Considering all of the above, what value will be created by farmland-elevating engineering? How can we measure the value? These questions deserve further attention.

At present, farmland-elevating engineering has been successfully applied in the construction practice of water conservancy projects, and relevant concepts have been gradually disclosed. Huang et al. [2] insisted that the farmland-elevating engineering can effectively solve the contradiction between the development of hydraulic resources and the population and land by enumerating three successful cases of farmland-elevating engineering, so as to create economic benefits for the society. Wan and Liu [3] took the pilot project of farmland-elevating engineering in the reservoir area of Xiajiang 
Hydroproject as an example and elaborated the technical route of carrying out farmland-elevating engineering. Xiong and Chen [4] studied the significance of farmland-elevating engineering and pointed out that the implementation of farmland-elevating engineering can reduce the inundation of the reservoir area and protect the cultivated land and effectively improve the soil structure by making some changes, thus effectively solving the contradiction between the development and utilization of water resources and the occupation of land. Yu [5] and Yang [6] systematically studied the concrete implementation process of farmland-elevating engineering from technical aspects, analyzed the suitable construction plans, summarized the construction experiences of farmland-elevating engineering, and provided solid technical support for large-scale lifting of fields. Hu et al. [7] explored the costs and benefits of farmland-elevating engineering by analyzing their structures, which provides good references for the owner to make decisions about farmland-elevating engineering. Most of the studies mentioned above are qualitative research, which is of significance for people to know more about farmland-elevating engineering, but it is hard to be convinced for the lack of quantitative analysis of the specific value of farmland-elevating engineering.

Farmland-elevating engineering can avoid the flooding of cultivated land outside the protection zone, make the land suitable for agricultural production and reduce the size of resettlement, therefore it can bring social value, ecological value and economic value at the same time. Until now, research on these values is still limited, and systematic research has not been reported yet. Deng et al. [8] carried out research on the soil fertility and water variation of paddy field under multi-structure farmland-elevating engineering, combining with Xiajiang Hydroproject. The results showed that the dry bulk density decreased, the field water holding capacity as well as the soil structure performances were improved to a certain extent. Based on the systematic summarization of related work on evaluation index system of soil and water conservation, Li et al. [9] established the evaluation indexes of prevention effect of soil and water loss caused by construction activities, using Analytic Hierarchy Process, and through on-site investigation of soil and water loss prevention in the construction of hydropower project. In comparison, the studies in other related fields have become more and more common, which can provide references for the value assessment of farmland-elevating engineering. It is considered that farmland biodiversity is the basis for the provision of multiple ecosystem services by farmland. Xie et al. [10] compared the impacts of different agricultural production models on the supply of farmland ecosystem services and proposed that future development of multi-purpose agriculture will maximize the well-being of farmland for people. Wall et al. [11] considered that soil biodiversity is very important to the biogeochemical function and ecological function of terrestrial ecosystems. Organ decay is one of the most important ecological services provided by soil biota. Based on the existing research, Dominati et al. [12] summarized the ecosystem services of soil natural assets. Zhang et al. [13] considered that farmland ecosystems provide human society with beneficial services such as food and fiber, water supply, soil conservation and aesthetic landscape and have some negative related services. Liu et al. [14] believed that the future research direction of the carbon cycle in farmland ecosystems should be exploring the carbon cycle mechanism of farmland ecosystems and examine the relationship between the nitrogen cycle, water cycle, microorganisms, and carbon cycle. Jiang et al. [15] carried out quantitative analysis on the economic losses caused by soil erosion in Xinjiang Uygur Autonomous Region, providing the basis for calculating the compensation standards for soil and water conservation in energy development, from the perspective of economic losses caused by soil erosion.

Comprehensive analysis of related work shows that researchers have focused on the engineering technology and cost-benefit impact of farmland-elevating engineering and lack benefit analysis on social, economic, and ecological value. In contrast, the cost of farmland-elevating engineering is relatively simple, while the value measurement is relatively complex. This article, from the overall point of view, carries on the value analysis and appraisal of the implementation of farmland-elevating engineering and tries to establish a relatively systematic value appraisal model, aiming to provide 
more reliable references for the decision-making of farmland-elevating engineering in the future water conservancy projects.

\section{Farmland-Elevating Engineering and Its Key Technologies}

During the construction process of a water conservancy project, emigration is often a key and difficult problem to solve. It is the foothold and starting point for the construction of the water conservancy project to ensure the project's success, to minimize the resettlement, to properly handle the vital interests of the resettlement masses, and to ensure the social stability of the reservoir area. Farmland-elevating engineering is put forward to reach these goals. It is to block up the arable land in the shallow submergence area of the reservoir as well as the cultivated land in the submergence area of the protected zone. Through engineering measures, the farmland is lifted to the non-submerged elevation of the reservoir and meets the requirements of agricultural production. Taking Xiajiang Hydroproject in Jiangxi Province for example, it applied farmland-elevating engineering mainly to rice farmland (commonly known as paddy fields in China). The entire farmland-elevating engineering has reduced the impact of resettlement and immersion and reduced the investment in flooded areas. At the same time, the sustainable utilization of cultivated land resources is protected, which is conducive to the construction of high standard farmland. In the implementation process, the key technological issues of farmland-elevating engineering include the soil structure, the construction parameters of the soil layer, and the construction process requirements [16,17].

\subsection{Soil Structure of Farmland-Elevating Engineering}

The typical strati-graphic structures used in farmland-elevating engineering projects consist of a top layer of tillage, a clay layer (or aquifer), and a bottom layer [17], which is blocked up, as shown in Figure 1.

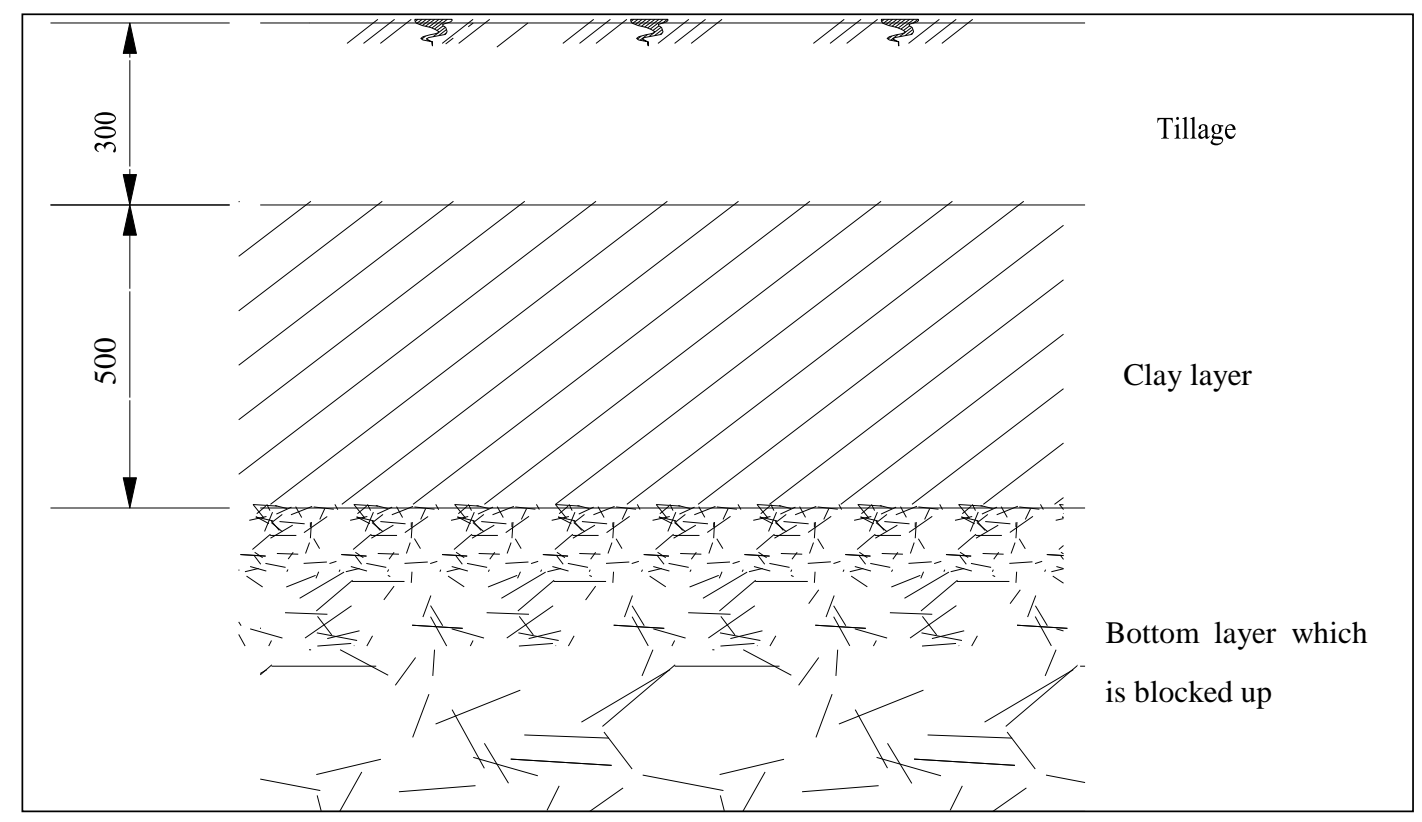

Figure 1. Stratum structure of farmland-elevating engineering.

\subsection{Soil Layer Construction Parameters in Farmland-Elevating Engineering}

In the process of construction of farmland-elevating engineering projects, the main parameters include soil layer thickness, permeability coefficient, compaction degree, relative density, and so on. In the Xiajiang Hydroproject, the tillage layer was peeled back using the stripped original tillage layer, and the thickness was set to meet the crop needs, which was finally determined to be $300 \mathrm{~mm}$. 
For the water retaining layer, that is the clay layer, the thickness of which is tentatively $300 \sim 500 \mathrm{~mm}$. The clay compaction thickness is not less than 0.90 , and its permeability coefficient is not greater than $i \times 10^{-4} \mathrm{~cm} / \mathrm{s}(1 \leq i<9)$, the compaction of the base layer viscous soil is not less than 0.85 , while the relative density of non-cohesive soil is not less than 0.6 , and the bottom layer is backfilled and blocked up by using sand graved or weathered material nearby.

\subsection{Soil Layer Construction Technology Requirements of Farmland-Elevating Engineering}

When carrying out the construction of the soil layer in farmland-elevating engineering projects, the surface tillage soil is peeled off first, and then the foundation material layer is filled. After the foundation material layer is checked for acceptance qualification, the clay soil and water retaining layer is filled. After the water retaining layer is checked and accepted, field works are carried out. Finally, the tillage soil was shipped back and flatted. The specific process is shown in Figure 2.

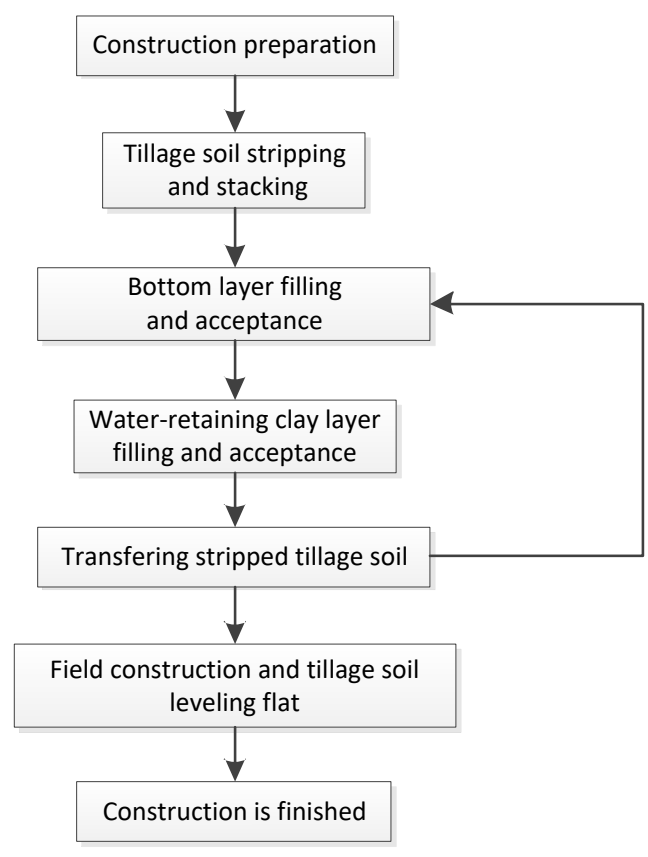

Figure 2. Construction process flow chart of farmland-elevating engineering.

\section{Farmland-Elevating Engineering Value System}

The implementation of farmland-elevating engineering will generally reduce the number of resettlers, reduce relocation and resettlement, reduce the inundation of cultivated land, and effectively solve the contradiction between the development of hydropower resources and the population and land. It provides substantial grain rations for peasants while saving a large amount of investment and ensures local environmental capacity to ease soil erosion. When the conditions are met, it is also conducive to the construction of high standard farmland by raising the fields, thereby reducing the planting cost and raising the living standard of local peasants. Therefore, the value of farmland-elevating engineering is multifaceted, and it can generally be attributed to social value, economic value, and ecological value.

\subsection{Social Value}

Through the implementation of farmland-elevating engineering, we can reduce the size of resettlement, reduce resettlement costs and land charges, and effectively solve the contradiction between water resources, population and land. At the same time, the original forms of scattered farmland will be integrated into a more competitive and higher development potential scientific 
farmland. From the point of view of current engineering conditions, the integrated farmland is more suitable for large-scale agricultural production and agricultural industrialization technology development, contributing to the formation of a "production-for-sale" integrated agricultural model in the subsequent agricultural development process. The social value of farmland-elevating engineering can be evaluated from reducing the resettlement scale and saving the permanent land acquisition.

\subsection{Economic Value}

Farmland-elevating engineering will avoid the flooding of cultivated land outside the protection zone. The cultivation and irrigation conditions of the farmland in the protected zone will be completely improved. The large amount of scattered farmland will be integrated to build high standard farmland, thus greatly reducing the planting cost and labor cost. The economic value of farmland-elevating engineering can be evaluated from high-standard farmland construction and crop planting.

\subsection{Ecological Value}

By raising the field, the gradient of farmland can be effectively reduced, and the soil erosion due to surface runoff can also be reduced. The fragmented cultivated land can be integrated into large-scale and complete farmland by carrying out farmland-elevating engineering. The increase of farmland area not only contributes to the farming operation, but also contributes to the realization of ecological diversity and ecological functions. Through farmland-elevating engineering, the soil structure can be significantly improved, which is conducive to the propagation and growth of soil microorganisms. The growth environment of crops can be reasonably improved, which helps to increase the follow-up crop yield. Thus, the indexes that reflect the farmland change after farmland-elevating can be taken as the main indexes to evaluate the ecological value of farmland-elevating engineering, mainly including the increased ecological benefits after land-lifting, the benefits resulting from reducing the interference of farmland ecosystem in the process of water and soil loss, and cost reduction in the restoration and maintenance of the ecosystem. Among them, the increased ecological benefits after land-lifting includes the value of atmospheric regulation, hydrological adjustment, waste disposal, biodiversity maintenance, soil and water conservation, and nutrient cycling sustainability.

Based on the above analysis, the value system of farmland-elevating engineering can be expressed as shown in Figure 3.

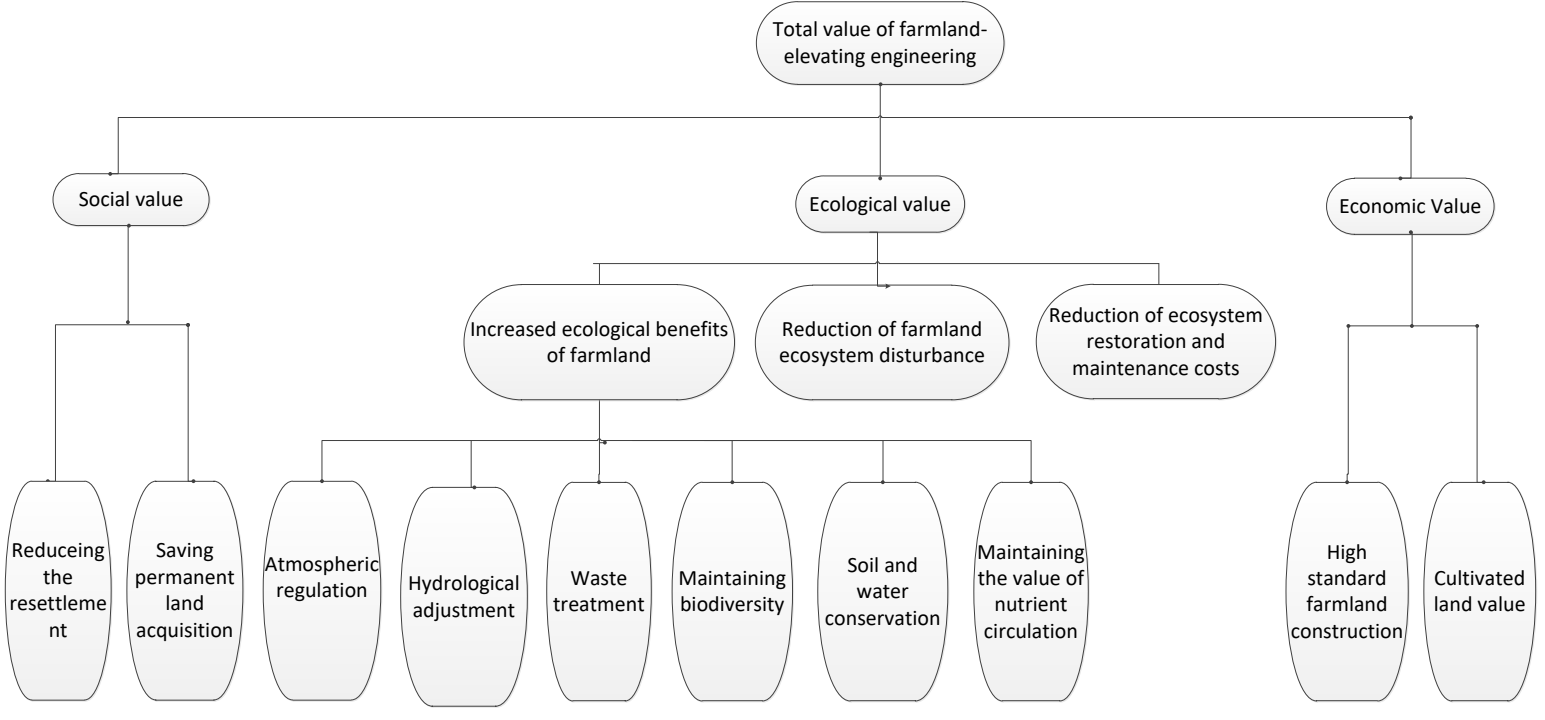

Figure 3. Value system of field-elevating engineering. 


\section{Value Measurement Model}

The value measurement of farmland-elevating engineering should contain social value, economic value and ecological value. Thus, what follows are corresponding models constructed to evaluate the value of farmland-elevating engineering, so as to provide theoretical support for the decision-making of farmland-elevating engineering projects.

According to the above analysis, the total value of farmland-elevating engineering $(W)$ includes social value, economic value and ecological value. Thus, it can be expressed as

$$
W=W_{1}+W_{2}+W_{3}
$$

In Equation (1), $W_{1}$ is social value; $W_{2}$ is economic value, and $W_{3}$ is ecological value.

\subsection{Social Value of Farmland-Elevating Engineering $\left(W_{1}\right)$}

According to Figure 3, the social value of farmland-elevating engineering, denoted as $W_{1}$, can be measured by the cost savings from reducing resettlement and cost savings from compensation for permanent land acquisition. Thus, it can be expressed as

$$
W_{1}=C_{1}+C_{2}
$$

In Equation (2), $C_{1}$ is cost savings from reducing resettlement, and $C_{1}=C_{11}+C_{12}+C_{13}$, where $C_{11}$ is the relocation funds for resettlement, $C_{12}$ is infrastructure construction funds, and $C_{13}$ is the resettlement fund for land acquisition. $C_{2}$ is the cost savings from compensation for permanent land acquisition.

\subsection{Economic Value of Farmland-Elevating Engineering $\left(\mathrm{W}_{2}\right)$}

The economic value of farmland-elevating engineering mainly results from high-standard farmland construction and crop planting, which can be evaluated by comparing the yield after and before the implementation of farmland-elevating engineering. Thus, it can be given by

$$
W_{2}=\left(S_{1}+S_{2}\right)\left(T_{0}+\Delta T\right) P
$$

In Equation (3), $S_{1}$ is the farmland-elevating area in shallow submerged zone, $S_{2}$ is the farmland-elevating area in protected zone, $T_{0}$ is the yield of crops per acre before farmland-elevating engineering, $\Delta T$ is crop yield increase per acre after the implementation of farmland-elevating engineering, and $P$ is the unit price of crop.

\subsection{Ecological Value of Farmland-Elevating Engineering $\left(W_{3}\right)$}

As discussed above, the ecological value of farmland-elevating engineering can be given by

$$
W_{3}=V_{1}+V_{2}+V_{3}+V_{4}+V_{5}+V_{6}+D_{1}+D_{2}
$$

In Equation (4), $V_{1}$ is the atmospheric regulation value, $V_{2}$ is the hydrological adjustment value; $V_{3}$ is the value of waste treatment, $V_{4}$ is the value of maintaining biodiversity; $V_{5}$ is the soil and water conservation value, $V_{6}$ is the value of maintaining nutrient circulation, $D_{1}$ is the interference cost savings of farmland ecosystem caused by soil and water loss, $D_{2}$ is the savings of recovery and maintenance costs of farmland ecosystem after soil erosion, $V_{1}=V_{11}+V_{12}+V_{13}$, where $V_{11}$ is the value of carbon fixation and oxygen production, $V_{12}$ is the value of climate regulation, and $V_{13}$ is the value of purifying air.

As an ecosystem, the ecological value of shallow submergence farmland zone, based on ecological service, can be measured by environmental value assessment to reflect its ecological benefits. 


\subsubsection{Atmospheric Regulation $\left(V_{1}\right)$}

According to the division and assessment of the value of global ecosystem services by Constanza et al. (1997), the value of atmospheric regulation includes the value of carbon fixation, oxygen production, climate regulation, and air cleaning.

1. Carbon fixation and oxygen production $\left(V_{11}\right)$

According to the photosynthesis equation, the ecosystem can absorb $1.63 \mathrm{~g} \mathrm{CO}_{2}$ and release $1.19 \mathrm{~g}$ $\mathrm{O}_{2}$ per $1.00 \mathrm{~g}$ of dry matters produced. To avoid repeated calculation, we should only calculate the value of $\mathrm{CO}_{2}$ absorption [18]. By calculating the biomass in the project area of farmland-elevating engineering, the converted amount of $\mathrm{CO}_{2}$ fixation by ecosystem can be got. We can get

$$
V_{11}=a \cdot a r \cdot s \cdot p \cdot o
$$

In Equation (5), $a$ is annual net biomass, $a r$ is planted area, $s$ is the carbon fixation coefficient, $p$ is equivalent to pure carbon coefficient, and $o$ is the cost of carbon fixation.

2. Climate regulation $\left(V_{12}\right)$

By carrying out the farmland-elevating engineering and unified planning for the project area, the climate in the field can be significantly improved. According to literature [19], the research results of various ecosystem service values by Xie (2008), and the average biomass of farmland ecosystem in China is $50 t$ [20]. Using reference method, we can get the value of climate regulation as follows.

$$
V_{12}=a \cdot c p \cdot a r
$$

In Equation (6), $a$ is the average biomass of the ecosystem, and $c p$ is the benchmark value of climate regulation.

\section{Purifying the air $\left(V_{13}\right)$}

Crops can catch dust and absorb $\mathrm{SO}_{2}, \mathrm{HF}$, and other harmful gases, they have good ability to purify the air significantly. According to the available research results, the amount of catching dust and absorbing harmful gas by irrigated fields, drylands, and broad-leaved forests can be obtained [21]. Based on the engineering cost of unit weight reduction of $\mathrm{SO}_{2}$ and dust, we can use shadow project method to calculate the total value of purified air, which can be given by

$$
V_{13}=a r \cdot\left(a c_{1}+a c_{2}\right) \cdot c t
$$

In Equation (7), $a c_{1}$ is the dust-holding capacity of crops, $a c_{2}$ is the ability of crops to absorb harmful gases such as $\mathrm{SO}_{2}$ and $\mathrm{HF}$, ct is the costs savings.

\subsubsection{Hydrological Adjustment $\left(V_{2}\right)$}

Farmland soil has the function of infiltrating water and storing water, and the adjustment of water quantity is similar to the nature of reservoir water storage. Therefore, the economic value of water storage and flood control in farmland can be determined by the storage cost of reservoir engineering, and the value of annual regulation storage capacity of farmland ecosystem can be calculated according to the storage cost of reservoir engineering (alternative engineering method). Thus, we can get

$$
V_{2}=w c \cdot s c .
$$

In Equation (8), wc is the amount of water storage; $s c$ is the storage capacity cost per unit water storage. 
The amount of water storage in farmland ecosystem is mainly related to its precipitation and evaporation. Therefore, the hydrological adjustment value of farmland is

$$
V_{2}=a r \cdot(a p-e c) \cdot s c .
$$

In Equation (9), ap is the precipitation, and $e c$ is the evaporation.

\subsubsection{Waste Treatment $\left(V_{3}\right)$}

Farmland ecosystems can eliminate and decompose the livestock waste. The current approach to the disposal and utilization of livestock waste is to directly return it to the field, which maintains the nutrient balance of the farmland and reduces environmental pollution and treatment costs. Waste disposal value is usually measured by the alternative market assessment technique (alternative cost method) as follows:

$$
V_{3}=f c \cdot a r .
$$

In Equation (10), $f c$ is the value of annual waste decomposition per unit area of farmland ecosystems.

\subsubsection{Biodiversity Maintenance $\left(V_{4}\right)$}

Farmland biodiversity is the basis of farmland ecosystem function and its providing ecosystem services. The value of biodiversity maintenance can be got by

$$
V_{4}=a r \cdot b v \text {. }
$$

In Equation (11), $b v$ is the value of biodiversity conservation per unit area.

\subsubsection{Soil and Water Conservation Value $\left(V_{5}\right)$}

Farmland is a core part of terrestrial ecosystems and plays an important role in the global biochemical cycle. Farmland-elevating engineering can reduce the slope of farmland, reduce soil erosion, and protect the soil and reduce the loss of soil fertility caused by soil erosion. According to the table of ecosystem service value per unit area of terrestrial ecosystem in China established in reference [20], the value of soil and water conservation in farmland can be obtained. The value of protecting the soil is replaced by the opportunity value of land abandonment.

$$
V_{5}=a r \cdot w v
$$

In Equation (12), wv is the value of farmland water and soil conservation per unit area.

\subsubsection{Nutrient Circulation Maintenance $\left(V_{6}\right)$}

Maintaining nutrient cycling is an important service in farmland-ecosystem support services and provides material assurance for crop production. The service value of farmland ecosystem in maintaining nutrient cycle can be evaluated by shadow price. Here, we denote $C_{N}$ as the cumulative amount of nutrient $N$ of all types of crops, $C_{P}$ is the cumulative amount of nutrient $P$ of various types of crops, $C_{K}$ is the cumulative amount of nutrient $K$ of various types of crops. (Expressed in terms of the amount of nutrients absorbed $(\mathrm{kg})$ in production of $100 \mathrm{~kg}$ economic yield.)

$$
V_{6}=\left(C_{N}+C_{P}+C_{K}\right) \cdot c o \cdot f p .
$$

In Equation (13), co is the crop yield, and $f p$ is the fertilizer price. 


\subsubsection{Reduction of Farmland Ecosystem Disturbance Caused by Water and Soil Erosion $\left(D_{1}\right)$}

After the shallow submergence zone is submerged, a large amount of soil and water loss will be caused by surface runoff, which will bring adverse effects of short time and large intensity on farmland ecosystems, resulting in large areas of land not being properly cultivated. Since the loss of soil can be controlled by the construction of silt retention project, we can use "Shadow Project" to calculate the economic loss due to soil loss. The shadow price is the investment cost for sediment intercepting works. Therefore, the economic loss from soil loss in shallow submergence area is the product of sediment loss $\left(\mathrm{m}^{3} / a\right)$ and the investment cost of intercepting per cubic meter silt project (yuan $\left./ \mathrm{m}^{3}\right)$, which can be expressed as

$$
D_{1}=c p \cdot s l
$$

In Equation (14), $c p$ is the unit of sand blocking construction cost; $s l$ is the amount of soil loss.

\subsubsection{Cost Reduction of Recovery and Maintenance of Farmland Ecosystem after Soil and Water Loss $\left(D_{2}\right)$}

In recent years, the scope of soil and water loss in China has been constantly expanding. The development and construction of large-scale water conservancy and hydropower projects will result in the inundation of the reservoir area, leading to serious soil erosion and loss and increasing recovery and maintenance costs. However, if farmland-elevating engineering is implemented, the cost will be greatly reduced. Therefore, the value of restoration and maintenance of ecological system after soil and water loss is determined through calculating the treatment cost after soil erosion of farmland ecosystem in the reservoir area.

$$
D_{2}=r c \cdot s l
$$

In Equation (15), $r c$ is the recovery cost per unit.

\section{Case Study}

Xiajiang Hroproject, located in Jiangxi Province of China, is the largest water projects in Jiangxi that can produce major social benefits, economic benefits, and ecological benefits from flood controlling, power generation, irrigation, and shipping. In this project, total reservoir capacity is 1.187 billion $\mathrm{m}^{3}$, its power station installed capacity is $360,000 \mathrm{KW}$, the average annual generating capacity is 1.142 billion $\mathrm{KW} \cdot \mathrm{h}$, and the channel is $1000 \mathrm{t}$-level, third-class. After the completion of this project, the flood control standard of the city where it is located will be raised from once in a century to once in 200 years. The flood control standards of the downstream embankments will be raised from once in 50 years to once in a century, which will ensure the flood control of the urban economic core zone to the maximum extent. It increases annual output of 1.142 billion $\mathrm{KW} \cdot \mathrm{h}$ clean power, effectively alleviating the shortage of power supply and demand, and channels the upstream by $77 \mathrm{Km}$, improving shipping conditions, increasing the area of downstream irrigation by $11 \mathrm{million} \mathrm{mu}$, and improving the irrigation area by 21 million mu.

In order to reduce the losses caused by the construction, the cultivated land in shallow submergence area of the reservoir is elevated, and through engineering measures, it is lifted up to the elevation of non-submerged reservoir. Farmland construction is carried out on the elevated cultivated land so as to meet the requirements of agricultural production. There are 15 farmland-elevating areas in the reservoir zone and 37,500 hectares of arable land was raised by $0.5-1.0 \mathrm{~m}$ on the basis of the normal water level in the reservoir, which is divided into the shallow inundation area outside the protection zone and the farmland in the protected zone. The elevation of the water conservancy project is $46 \mathrm{~m}$, which is equivalent to the normal water level. The range of farmland-elevating engineering outside the protection zone is mainly the shallow submerged area, that is, the farmland elevation of $43-46 \mathrm{~m}$ is raised to be higher than the normal water level of the reservoir by $0.5-1 \mathrm{~m}$, a total of 23,900 $\mathrm{mu}$, in order to ensure that these farmlands can be properly cultivated after the impoundment of the reservoir. Farmland-elevating in the protected area is the ploughing area affected by the high 
water level after the reservoir is impounded because the quality and yield of farmland will be reduced by this effect. Therefore, the use of farmland-elevating engineering aims to achieve the purpose of protecting the existing arable land.

As for the Xiajiang Hroproject, related ecological engineering parameters are shown in Table 1.

Table 1. Related ecological value parameters of the Xiajiang Hroproject.

\begin{tabular}{ccl}
\hline Number & Parameter & \\
\hline 1 & $a r$ & Planting area: $37,500 \mathrm{mu}\left(2500 \mathrm{hm}^{2}\right)$ \\
2 & $a$ & Farm average annual net biomass: $16.5 \mathrm{t} / \mathrm{hm}^{2}$ \\
3 & $s$ & Carbon fixation coefficient: 1.63 \\
4 & $p$ & Equivalent to pure carbon factor: 0.2727 \\
5 & $o$ & Carbon fixation costs (carbon tax rate): 1026 yuan $/ \mathrm{t}$ \\
6 & $c p$ & Farmland ecosystem climate regulation: 435.63 yuan $/ \mathrm{hm}^{2}$ \\
7 & $a c 1$ & Dust retention capacity of crops: $50 \mathrm{~kg} / \mathrm{hm}{ }^{2}$ \\
8 & $a c 2$ & Harmful gases $\left(\mathrm{SO}_{2}, \mathrm{HF}\right.$, etc.) absorption capacity: $39 \mathrm{~kg} / \mathrm{hm}^{2}$ \\
9 & $a p$ & The average annual precipitation in the reservoir area: $1600 \mathrm{~mm}$ \\
10 & $e c$ & The average evaporation of the reservoir area: $1100 \mathrm{~mm}$ \\
11 & $s c$ & Reservoir water storage capacity cost per unit water storage: $0.75 \mathrm{yuan} / \mathrm{m}^{3}$ \\
12 & $f c$ & Absorbing waste decomposition per unit area of farmland ecosystems: $624.25 \mathrm{yuan} / \mathrm{hm}{ }^{2}$ \\
13 & $b v$ & The value of biodiversity conservation per unit area: 458.08 yuan $/ \mathrm{hm}^{2}$ \\
14 & $w v$ & The value of farmland water and soil conservation per unit area: $660.18 \mathrm{yuan} / \mathrm{hm}^{2}$ \\
15 & $C_{N}$ & $C_{N}: 3.2 \mathrm{~kg} / 100 \mathrm{~kg}$ crop \\
16 & $C_{P}$ & $C_{P}: 1.5 \mathrm{~kg} / 100$ kg crop \\
17 & $C_{K}$ & $C_{K}: 4 \mathrm{~kg} / 100$ kg crop \\
18 & $f P$ & Fertilizer average price: 2549 yuan $/ \mathrm{t}$ \\
19 & $s l$ & The amount of soil loss: $92,500 \mathrm{~m}{ }^{3}$ \\
20 & $c p$ & The sand blocking construction cost per unit: $1005 \mathrm{yuan} / \mathrm{m}^{3}$ \\
21 & $r c$ & The recovery cost per unit: 4271.25 yuan $/ \mathrm{m}^{3}$ \\
\hline
\end{tabular}

After the implementation of the water conservancy project, there were 23,900 mu of cultivated land in shallow submergence zone and 136,000 mu of cultivated land in the protected zone that were also affected by the high water level immersion. Since the closure of the dam, the paddy field carrying out farmland-elevating engineering has been increasing its output for three years in a row. The average annual rice output of about $800 \mathrm{~kg} / \mathrm{mu}$ has reached an average annual output of $900 \mathrm{~kg} / \mathrm{mu}$. According to the standard of land acquisition and house demolition compensation and fee collection, the unit price of paddy field land acquisition is 31,500 yuan/mu, and that of dry land and house site is $21,000 \mathrm{yuan} / \mathrm{mu}$, and the unit price of woodland is $11,025 \mathrm{yuan} / \mathrm{mu}$. Since the vast majority of farmland-elevating engineering involved are paddy fields, the land acquisition costs for the project are unified at 31,500 yuan/mu. In addition, if farmland-elevating engineering is not carried out, according to the provincial government's compensation standards for land acquisition to measure, the relocation funds required reach 840 million yuan, infrastructure construction funds are 180 million yuan, and resettlement land acquisition funds are 40 million yuan. Also, unit price of the crop is 30,000 yuan/mu.

Based on the above data, we can calculate the social value, economic value and ecological value of farmland-elevating engineering respectively. The results are as follows.

\subsection{Social Value}

According to the above method for measuring social value, the resettlement fee will be reduced to 1.06 billion yuan, and the compensation for permanent land acquisition will be 1.18 billion yuan after the land-elevating measures are taken, thus the total social value of the project will be 2.24 billion yuan.

\subsection{Economic Value}

Due to the three-year increase in the paddy fields carrying out farmland-elevating engineering, only the annual economic value of the paddy fields after the stable crop yields have been calculated. 
Calculating by using the above measurement method, we can get the result that the annual cultivated land planting value after high standard farmland construction is 101.25 million yuan.

\subsection{Ecological Value}

The calculation results are shown in Table 2.

Table 2. Ecological value calculation of farmland-elevating engineering.

\begin{tabular}{|c|c|c|c|c|c|}
\hline & & lue Type & & $\begin{array}{l}\text { Value Measure } \\
\text { (million yuan) }\end{array}$ & $\begin{array}{c}\text { Total } \\
\text { (million yuan) }\end{array}$ \\
\hline \multirow{3}{*}{$\begin{array}{l}\text { Ecological } \\
\text { value }\end{array}$} & \multirow{2}{*}{$\begin{array}{l}\text { The ecological } \\
\text { benefits of } \\
\text { farmland after } \\
\text { farmland-elevating } \\
\text { engineering } \\
\text { increased }\end{array}$} & $\begin{array}{l}\text { Atmospheric } \\
\text { regulation }\end{array}$ & $\begin{array}{c}\text { Carbon sequestration oxygen } \\
\text { Climate regulation } \\
\text { Purifying the air }\end{array}$ & $\begin{array}{c}1881.24 \\
5445.38 \\
7.98\end{array}$ & \multirow{3}{*}{$57,519.39$} \\
\hline & & $\begin{array}{r}\text { Hy } \\
\mathrm{M} \\
\text { Soil } \\
\text { Value of mair }\end{array}$ & $\begin{array}{l}\text { logical adjustment } \\
\text { aste treatment } \\
\text { tain biodiversity } \\
\text { water conservation } \\
\text { ning the nutrient circulation }\end{array}$ & $\begin{array}{c}937.50 \\
156.07 \\
114.52 \\
165.05 \\
3.34\end{array}$ & \\
\hline & \multicolumn{3}{|c|}{ Reduction of farmland ecosystem disturbance } & $\begin{array}{c}9296.25 \\
39,509.06\end{array}$ & \\
\hline
\end{tabular}

According to the calculation results, we can find out that the social, economic, and ecological values of this project are very impressive. Among them, the social value reached 2.24 billion yuan. According to related references, the project cost a total of 471.896 million yuan in farmland-elevating engineering [7]. Thus, we can conclude that the farmland-elevating engineering can produce greater benefits.

\section{Conclusions}

In the construction of water conservancy projects, the implementation of farmland-elevating engineering is conducive to solving the contradiction between the development of hydropower resources and population and land, reducing the number of resettlement, saving the total investment in the project, helping to ease soil erosion, and improving the agricultural environment. It helps to properly handle the vital interests of the resettler masses and ensure the social stability of the reservoir area at the same time of ensuring project success. Therefore, farmland-elevating engineering has important practical value. Considering social value, economic value and ecological value of farmland-elevating engineering, this paper constructs the value system and measurement model of farmland-elevating engineering. Among them, the social value of farmland-elevating engineering mainly resulted from reducing the resettlement scale and saving the permanent land acquisition. The economic value can be evaluated from high-standard farmland construction and crop planting. While the ecological value can be reflected by the farmland change after farmland-elevating, including the increased ecological benefits after farmland-elevating, the benefits resulting from reducing the interference of farmland ecosystem in the process of water and soil loss, and cost reduction in the restoration and maintenance of the ecosystem, etc.

Taking the Xiajiang Hroproject in Jiangxi Province of China as an example, this paper calculates the social value, economic value, and ecological value of farmland-elevating engineering respectively and analyzes the feasibility and economic applicability of farmland-elevating engineering. The results show that the application of engineering techniques to elevate the field can produce greater value. The social, economic, and ecological benefits brought by farmland-elevating engineering are reflected in many aspects.

In the proposed value measurement model for farmland-elevating engineering, this paper only selects some key indicators that cannot yet cover the full value but can reflect the overall value of farmland-elevating engineering to a great extent. In the next step of research and practice, we should consider more and more indicators that reflect the value of agricultural sightseeing tourism step by step according to an actual situation. In doing so, we can further improve the quantification of ecological 
benefits and further optimize the value assessment model to make it more promising for the scientific judgment for application of farmland-elevating engineering.

Author Contributions: J.D. conceived and designed the study, and built the framework. W.Z. completed the paper in English and revised it critically for important intellectual content. L.H. gave many good research advices and revised the manuscript.

Acknowledgments: The authors would like to acknowledge the supports from the National Natural Science Foundation of China (Project No. 71402045) and the Fundamental Research Funds for the Central Universities (Project No. 2017B18114) that funded this research.

Conflicts of Interest: The authors declare no conflicts of interest.

\section{References}

1. Yu, J.Y. Problems of Land Acquisition and Resettlement for Large and Medium-sized Water Conservancy and Hydropower Projects. China Land 2006, 7, 38-43.

2. Huang, W.H.; Wu, S.H. Application of the "lift the field" measurement in the submerged treatment of reservoirs. Jiangxi Water Conserv. Sci. Technol. 2001, S2, 34-35.

3. Wan, D.W.; Liu, Z.B. Study on Engineering Methods of Lifting up Field in Xiajiang River Water Conservancy. Water Conserv. Tech. Superv. 2012, 3, 28-30.

4. Xiong, J.; Chen, W. Application of field lifting in water conservancy project. Jiangxi Water Conserv. Sci. Technol. 2016, 2, 132-134.

5. Yu, Y.P. Application of Lift-up Construction Technology in Water Conservancy Engineering. Water Conserv. Tech. Superv. 2014, 6, 76-78.

6. Yang, X.H. The implementation of the pilot project of the Weigou Field-Lifting of the Xiajiang River Water Control Project. In Proceedings of the Seventh National Forum on the Management of Lake and Water Ecology Civilization, Guangzhou, China, 10-12 April 2015.

7. $\mathrm{Hu}, \mathrm{X}$. Cost-benefit analysis of Taitian project in shallow flooded area of Xiajiang Water Conservancy Project. China Hydropower Electr. 2013, 12, 18-21.

8. Deng, H.L.; Xu, Y.Q.; Xie, H.W.; Wang, S.H.; Liu, F.P.; Li, A.; Li, H. Research on the variation rules of soil fertility and moisture to the reservoir area of Xiajiang Water Conservancy Project. China Rural Water Hydropower 2017, 3, 187-190.

9. Li, X.H.; Cun, Y.K.; Liu, X.Q.; Chen, Q.B. An index system for evaluating soil erosion control efficiency in hydropower project. Soil Water Conserv. Technol. 2010, 2, 15-17.

10. Xie, G.D.; Xiao, Y. Review of agro-ecosystem services and their values. Chin. J. Eco-Agric. 2013, 21, 645-651. [CrossRef]

11. Wall, D.H.; Bardgett, R.D.; Kelly, E.F. Biodiversity in the dark. Nat. Geosci. 2010, 3, 297-298. [CrossRef]

12. Dominati, E.; Patterson, M.; Mackay, A. A framework for classifying and quantifying the natural capital and ecosystem services of soils. Ecol. Econ. 2010, 69, 1858-1868. [CrossRef]

13. Zhang, W.; Ricketts, T.H.; Kremen, C.; Carney, K.; Swinton, S.M. Ecosystem services to agriculture. Ecol. Econ. 2007, 64, 253-260. [CrossRef]

14. Liu, Y.; Chen, M.P.; Chen, J.N. Progress and perspectives in studies on agro-ecosystem carbon cycle model. Chin. J. Agric. Eng. 2015, 31, 1-9.

15. Jiang, X.; Gao, Z.L.; Shen, L.M. Analysis and evaluation method of soil and water loss in Xinjiang area of our country and the loss quantification, China. J. Cap. Norm. Univ. 2014, 35, 66-78.

16. Technical Supervision Bureau of Quality and Technical Supervision of Jiangxi Province. Technical Code for Carrying out Field Engineering in Reservoir Area of Water Conservancy (DB 36/T 853-2015); China Water and Power Press: Beijing, China, 2016.

17. Jiangxi Province Xiajiang River Water Conservancy Project Construction Headquarters. Jiangxi Province Xiajiang River Water Conservancy Project-Major Engineering Technologies; China Water and Power Press: Beijing, China, 2016.

18. Zhang, S.H.; Zhao, G.Z.; Tian, Y.Z.; Xuan, L.Y. Study on value the ecological environment valuation of forestry resources. J. Yanbian Univ. 2001, 2, 126-134.

19. Xie, G.D.; Zhen, L.; Lu, C.X.; Xiao, Y.; Chen, C. Expert knowledge based valuation method of ecosystem services in China. J. Nat. Resour. 2008, 23, 911-919. 
20. Zhang, X.L. Study on the Eco-Benefits of Land Consolidation upon the ESV Theory; Huazhong Agricultural University: Wuhan, China, 2009.

21. Ma, X.H.; Sun, G.N.; Ren, Z.Y. The values of vegetation purified air and its measure in Xi'an city. Resour. Environ. Arid Reg. 2002, 16, 83-86. 